and certain of his chapters are in the highest degree interesting. His chapter on the origin of coal is perhaps more interesting than any other, and is full of suggestive reasoning. I have not seen the work cited in any of our treatises on geology, and yet the opinions of such an eminent chemist must have some weight in the treatment of problems wherein chemistry alone can furnish a satisfactory solution.

Dublin, October 22

\section{Suicide of Scorpions}

THE self-destruction of the scorpion when hard-pressed is ungrustionable. I have on several occasions invited sceptics to witness the tragedy (!) in this part of Europe.

The scorpion we frequently meet with in and about "Sierra Morena" under stones and in crevices, is a large light-brown species ofter more than two inches from head to sting.

Having procured one I have placed it in a circle of glowing charcoal embers a foot or so in diameter; after vain attempts to get away it raises its tail over its back, pierces its head with its sting and dies, precisely in the way described by Dr. Thomson (NATURE, vol. Xx. p. 577).

Provincia Jaen, Linares, Spain, October 20

\section{Superficial Earthquakes}

CAN any correspondent oblige me with an explanation of the following facts? The earthquake which took place at Virginia City some time ago was not felt by the workmen in the mines. Some years ago a much more violent earthquake shook the town, breaking chimneys, overthrowing houses, and so on. But it was hardly to be noticed in the mines; indeed, not at all in the deeper shafts.

Oct ber 16

\section{Coloured Lightning}

ABOUT 4. P. . to-day we had a pretty severe thunderstorm, accompanied by heavy rain, and the entire heavens were overcast by one unbroken cloud; three or four flashes of lightning were of a distinct blue colour, and then followed a flash of beautiful rose colour, succeeded by more flashes of blue lightning. Will some of your correspondents explain the cause of change of colour? and oblige

Welland, Ontario, Canada, September 28

"MEMORIA."-The correspondent who signs herself thus must send her name if she wishes her letter to be inserted.

\section{OUR ASTRONOMICAL COLUMN}

THE SATEllites Mimas AND Hyperion.-The following are approximate times of the greatest western elongations of Mimas during the first week in November :-

$$
\begin{aligned}
& \text { Nov. I ... I4 } 24 \text { G.M.T. } \\
& \begin{array}{lllllll} 
& 2 & \ldots & 13 & \mathrm{r}
\end{array} \\
& \begin{array}{cccccc}
\text { Nov. } & 4 & \ldots & \text { ho } & \text { I } & \text { I5 G.M.T } \\
\Rightarrow & 5 & \ldots & 8 & 52 & \\
\Rightarrow & 6 & \ldots & 7 & 29 &
\end{array} \\
& \begin{array}{llllll}
\prime \prime & 3 & \ldots & \text { II } & 1 \\
, 8 & 3
\end{array}
\end{aligned}
$$

Observations of Hyperion during the present opposition are required before a reliable ephemeris of this satellite can be furnished. The true motion of the peri-saturnium is yet doubtful, unless Prof. Asaph Hall has been able to decide tupon it from later observations than have been published. As we have stated before, Mr. Marth some years since conjectured that it might be as great as $+75^{\circ}$ annually, and this rate of motion accords with Bond's determination of the place of the peri-saturnium in 1848 and Hall's results from Mr. Lassell's observations in 1852 , and his own in 1875 . So far as we know the Washington measures of 1878 are not yet published; probably they may throw more light upon the subject.

ANUARIO DEL OBSERVATORIO DE MADRID.-The sevcnteenth volume of this compilation (for I 879 ) reaches us late in the year. It is one of those useful compendiums of which the Annuaire du Bureau des Longitudes is probably the oldest, and may be taken as the type. Astronomical phenomena and details occupy a considerable space, and the volume is therefore fitly noticed in this column, but there is a great amount of miscellaneous information, geographical, meteorological, physical, and otherwise, which will recommend it to a larger class of readers. We remark some few points to which exception might be taken on the score of want of accuracy or completeness; thus the independent discovery of Hyperion by Mr. Lassell is not recorded, and the number of Uranian satellites is set down as eight, though four are queried with good reason. The discovery of Tuttle's comet is dated in 1858 , no mention being made of its appearance in 1790 . It is doubtless through a misprint that Encke's comet is stated to have appeared in $\mathbf{I} 695$. Many of the miscellaneous tables are very full, as, for example, those of the altitudes of mountains in all parts of the world, the length of rivers, and the meteorological conditions in various parts of the peninsula, and as regards Spanish science, \&c., the volume is no doubt to be considered authoritative. There are many who have occasion to consult works of this kind, who may like to have their attention directed to the present publication of the Royal Observatory at Madrid.

A New Private Observatory. - Observatories erected, equipped, and maintained in actirity by private individuals are numerous in this country, and, as will appear from Prof. Holden's recent report, there are many of them in the United States; but the number of known observatories of this class upon the continent of Europe is not great, and the more interest therefore attaches to the addition of a new one to the list. Dr. Jedrzejewicz gives some account of an observatory he has constructed at Plónsk, about 37 miles from Warsaw, or in lat. $52^{\circ} 37^{\prime} 39^{\prime \prime}$, and long. $20^{\circ} 30^{\prime} 59^{\prime \prime} \mathrm{E}$. of Greenwich. The principal instrument is an equatorially-mounted refractor by Steinheil, of 6.4 inches aperture, to which are atiached filar and other micrometers, and a spectroscope. Acting upon the advice of Dr. Vogel of Potsdam, Dr. Jedrzejewicz has the intention of devoting his time mainly to the measurement of double-stars, selecting such objects as are well within the power of his telescope; indeed, he has already made a considerable advance in this direction, having secured 860 complete observations of 170 double or compound stars, the result of some 8,500 separate measures, and with the view to enable astronomers to judge of the amount of confidence to be placed in the observations that may be published from Plónsk, he has given a comparison of his measures of a number of stars, which do not exhibit change, with those of Struve and others, and the comparison will tend to induce reliance upon his work. One remark we may make which bears generally upon the selection of objects for measurement with such an aperture as Dr. Jedrzejewicz possesses: it appears to have been too much the custom with the generality of observers who devote themselves to double-star astronomy, to accumulate a large number of measures of well-known, we may almost say, historical binaries, to the neglect of other objects, equally within the scope of their instruments, and equally deserving of attention. A carefully-considered list of stars is an essential in the actual state of this branch of the science, if the labours of the observer are to possess their utmost attainable value, in the future. The numerous discoveries of Mr. Burnham in particular confirm us in this view; his various lists exhibit many stars which it is highly desirable to keep under observation, and which do not yield in point of interest to other better-known binaries.

\section{GEOGRAPHICAL NOTES}

THE Japan papers report, with expressions of great regret, the loss, of which we have already had news by telegraph, of the $A . E$. Nordenskjold, the little vessel 
which M. Sibiriak of fitted out for the relief of the $V e g a$. The vessel left Yokohama on August r, and was lost on August 5 , near Nemora, at the north-eastern point of the island of Yesso. The A. E. Nordenskjold was commanded by Capt. Sengstake, an Arctic explorer of repute, who, when called to this duty, had arranged to accompany Dr. Otto Finsch in his expedition to the Pacific. The crew consisted of picked Arctic sailors, and there were also on board M. Gregorief, representing the Russian Geographical Society, and Herr Dankelmann, of Leipsic, the delegate of the Bremen Society. All on board were saved and were stated to be returning to Yokohama.

DR. OSCAR LENZ will shortly start on a tour to Marocco by order of the German African Society.

Les Missions Catholiques has published, in its last two numbers, some notes on Assam and the neighbouring countries, which have been furnished by a Roman Catholic missionary. By a singular coincidence the second instalment, containing an account of the Naga tribes, appeared just at the time when news arrived of Mr. Damant's murder in the Naga Hills.

THE new Bulletin of the Sociétê de Géographie Commerciale, of Bordeaux, contains a paper of some interest, by M. G. Revoil, entitled "Le Pays des Çomalis" Medjourtines," which is accompanied by an outline map of that portion of Africa.

THE members of the Geographical Society of Algiers held their first meeting in the Hotel de Ville of that city on October 22 , to elect their officers.

THE just-published Bulletin (for August) of the Paris Geographical Society, contains the itinerary of the Abbe Desgodins, of his journey from Pa-tang to Ta-tsien-len and back in 1877 , and an account of the journeys of Père Duparquet in South Africa, by the Abbé Durand. There are some interesting letters between Dr. Rohlfs, Dr. Stecker, M. Duveyrier, and M. Marié Davy, concerning observations made in North Africa by Dr. Stecker, on electrical and other natural phenomena.

MR. STANFORD has just published a large scale map of Japan, which forms probably the best map of the country now in existence. It has been compiled by Mr. Knipping; whose official position in Japan has given him exceptional advantages for obtaining the necessary material. He has used the native Japanese surveys, which we believe are wonderfully accurate, data collected during his own extensive journeys in the country, travellers' narratives, and consular reports. The map is on the scale of seventeen miles to an inch, and is creditable to author and publisher, and certain to prove useful to all who have dealings with the country.

MR. EDWARD F. SANDEMAN will shortly publish, through Messrs. Griffin and Farran, an account of his travels in South Africa, under the title of "Ten Months in an Ox Waggon; Reminiscences of Boer Life." A special feature of the book will be the description of the home life of the Boers and their chief characteristics, and it will contain half-a-dozen chapters of shooting experiences in the country to the far east of the Transvaal, with accounts of the various big game of that region. A visit to the gold fields is also described, and some account will be given of the life of the miners. The volume will contain a map of the country.

\section{KEW GARDENS}

T $T$ is highly desirable that the public should be fully acquainted with the real objects of the establishment of which we have the annual report before us, as a very imperfect impression on the subject is prevalent. That object is not simply to collect as many forms of vegetation

$x$ " Report of the Progress and Condition of the Royal Gardens at Kew during the Year $1878 . "$ as admit of cultivation, with a view to facilitate the studies of botanists, whether young or old, much less to make mere collections of plants without any ulterior view; but while its unequalled herbarium and diligent staff are enabled to promote botany as a science, it has in view the rational recreation of multitudes and the accompanying improvement in taste, from the familiarity with exquisite forms and combination of colouring, aided by the attendant prevalence of order in each department; while in an economic point of view there are facilities for the investigation of diseases which affect our commerce or manufactures, unequalled facilities of diffusing through our colonies productions which may prove of vast importance to their interests, inquirers at home being able at once, through the museum and its curator, to become acquainted with matters in which their factories are more or less concerned, and thus to obtain information which in many cases has proved the source of national advantage. At the same time there are great opportunities for young cultivators gaining such a knowledge of the structure and intimate nature of plants as will not only be useful to themselves and their employers, but which has a tendency to improve by example the numerous tribe of gardeners who are too often deficient in the very knowledge which is of the utmost importance to successful cultivation. The interchange of plants and seeds also is carried on to a great extent at $\mathrm{Kew}$, which is now the acknowledged ultimate medium for all communications from abroad with reference to what may be called industrial plants. The mass of correspondence which is carried on in this very useful department is almost overwhelming. Amongst other things, india-rubber plants, coffee, and quinine-producing barks, have received peculiar attention, respecting which interesting details will be found in the report. The cinchona plantations, not less than those of coffee, are every day of increasing importance, much of which is due to our national establishment at Kew. Not only have pains been taken to introduce the most improved forms of the coffee-plant, but the disease which is ravaging the coffee-plantations in Ceylon has been diligently studied by Mr. Abbay, whose observations were commenced in Ceylon in company with Mr. Thwaites. The first step to combating with diseases is doubtless an efficient knowlege of their nature, and it appears that the observations of these gentlemen and $\mathrm{Mr}$. Morris have been attended with success in the application of proper remedies. Full figures are given in the report of the structure and nature of the coffee mildew by $\mathrm{Mr}$. Abbay. This is not the only good work which has been done at the new laboratory during the past year, where the writer of the present notice has more than once profited by the facilities which it affords for observation.

It is not to be expected that the introduction of useful plants will be equally successful everywhere. Much depends on the intelligence and care of the recipients, even when there is no inaptability of climate. We anticipate in future reports that the diffusion of other matters less generally known will be recorded as at once successfu? and important. There is, perhaps, no set of plants of more importance than those which produce india-rubber. Attention was drawn years ago to the wasteful destruction of native plants and the necessity of greater care being taken with the forests in which these trees abound, and a committee was appointed for the furtherance of this: object. The trees which produce this valuable substance are various, and belong to very different natural orders, and the extension of different sources of production, in consonance with different varieties of climate, has been a matter of constant anxiety at Kew. Here, again, a perusal of the report before us will be highly instructive.

Besides the matters above mentioned, at the close of the report many suggestions of sources of possible utility are given, which will be read with much interest, amongst which we may mention the Rain-tree of Peru, the South 